\title{
Serum D-dimer, albumin and systemic inflammatory response markers in ovarian clear cell carcinoma and their prognostic implications
}

Wei Chen ${ }^{1,2+}$, Siyuan Zhong ${ }^{3,4 \dagger}$, Boer Shan ${ }^{1,4+}$, Shuling Zhou ${ }^{3,4}$, Xiaohua Wu $u^{1,4}$, Huijuan Yang ${ }^{1,4^{*}}$ and Shuang Ye $e^{1,4^{*}}$

\begin{abstract}
Background: This study attempts to evaluate whether preoperative systemic inflammatory response (SIR) markers or other hematological variables, such as albumin, D-dimer, and carbohydrate antigen 125, play roles in predicting chemotherapy response and survival outcome in patients with ovarian clear cell carcinoma (OCCC).

Methods: Preoperative leukocyte differential counts, as well as platelet, serum albumin, plasma D-dimer and CA125 levels, were measured in patients with FIGO IC-IV ovarian clear cell cancer. The correlations of these hematological biomarkers with clinicopathological features, chemotherapy response, and survival outcomes were further analyzed. Survival time was estimated using the Kaplan-Meier model, whereas Cox regression was conducted for multivariate analysis.

Results: Among the 84 patients, 28.6\% were classified as platinum resistant, and $69.0 \%$ were platinum sensitive. Preoperative CA125, albumin, and D-dimer levels; neutrophil to lymphocyte ratios (NLR); and monocyte to lymphocyte ratios were significantly correlated with $\mathrm{FIGO}$ stage, residual tumor, and platinum response. Platelet to lymphocyte ratio was not related to platinum response $(P=0.060)$. The median follow-up time was 28 months (range, 1 to 128 months). Preoperative CA125, albumin, and D-dimer levels were significant prognostic factors for overall survival (OS) and progression-free survival (PFS). In the univariate analysis, only NLR exhibited prognostic significance for PFS ( $P=0.007$ ). Multivariate analysis indicated that $D$-dimer $>3.27$ ( $P=0.001$ for OS; $P=0.040$ for PFS) and albumin $<39.6$ ( $P=0.005$ for OS and $P=0.041$ for PFS) retained significance.

Conclusions: Preoperative NLR has some predictive value for platinum resistance in patients with IC-IV stage OCCC but has little predictive effect on prognosis. Elevated D-dimer and reduced albumin might be potential biomarkers for worse response to first-line platinum-based chemotherapy and poor clinical outcomes.
\end{abstract}

Keywords: Ovarian neoplasms, Clear cell carcinoma, D-dimer, Albumin, Neutrophil to lymphocyte ratio, Platinum resistance, Recurrence, Survival

\footnotetext{
*Correspondence: huijuanyang@hotmail.com; mendy_ye@126.com

'Wei Chen, Siyuan Zhong and Boer Shan contributed equally to this work. 'Department of Gynecologic Oncology, Fudan University Shanghai Cancer Center, Shanghai, China

Full list of author information is available at the end of the article
}

C C The Author(s). 2020 Open Access This article is licensed under a Creative Commons Attribution 4.0 International License, which permits use, sharing, adaptation, distribution and reproduction in any medium or format, as long as you give appropriate credit to the original author(s) and the source, provide a link to the Creative Commons licence, and indicate if changes were made. The images or other third party material in this article are included in the article's Creative Commons licence, unless indicated otherwise in a credit line to the material. If material is not included in the article's Creative Commons licence and your intended use is not permitted by statutory regulation or exceeds the permitted use, you will need to obtain permission directly from the copyright holder. To view a copy of this licence, visit http://creativecommons.org/licenses/by/4.0/ The Creative Commons Public Domain Dedication waiver (http://creativecommons.org/publicdomain/zero/1.0/) applies to the data made available in this article, unless otherwise stated in a credit line to the data. 


\section{Background}

Epithelial ovarian cancer (EOC) is the eighth most common cause of female cancer death worldwide [1]. Ovarian clear cell carcinoma (OCCC) is a distinct histological subtype that accounts for $5-25 \%$ of all EOC and is more commonly observed in Asian women [2, 3]. Although the prognosis for patients with stage I OCCC is relatively good, patients with stage IC-IV OCCC presents much poorer prognoses than patients with serous carcinoma due to its disease aggressiveness and chemotherapy resistance $[3,4]$. The factors, such as the International Federation of Gynecology and Obstetrics (FIGO) stage, residual tumor, and platinum response, influence treatment outcomes in OCCC [5]. However, these factors are limited to be confirmed after surgery or chemotherapy. The current standard treatment for EOC remains surgery and platinum-based cytotoxic chemotherapy. Generally, OCCC patients receive routine treatment, while platinum-resistant patients derive minimal benefit from it but increased morbidity and costs. Clinically useful preoperative prognostic factors for early identification of chemotherapeutic responses are needed to improve clinical outcomes and decrease toxicity in stage IC-IV OCCC.

Albumin, D-dimer, and systemic inflammatory response (SIR) markers, such as neutrophil-to-lymphocyte ratio (NLR), monocyte-to-lymphocyte ratio (MLR) and plateletsto-lymphocyte ratio (PLR), are easily accessible and inexpensive to evaluate before initial treatment. Albumin is a significant prognostic factor for overall survival of ovarian cancer [6]. Plasma D-dimer levels, which are significantly elevated in patients with OCCC, are associated with the incidence of deep venous thrombosis [7] as well as clinical progression and poor prognosis in malignancies, including ovarian cancer $[8,9]$. Numerous studies have shown that elevated NLR is linked to poor prognosis among patients with solid tumors, including gynecologic cancers [10, 11], and markers of systemic inflammatory response could provide useful prognostic information of overall survival in patients with OCCC $[12,13]$.

However, evidence for the use of available biomarkers preoperatively as predictors of outcome in patients with OCCC receiving chemotherapy is lacking. The purpose of the current study was to determine whether preoperative hematological biomarkers, such as albumin, Ddimer, and carbohydrate antigen 125 (CA125), or SIR markers could play a role in predicting response to chemotherapy and survival outcome.

\section{Materials and methods \\ Patients}

The institutional review board approved the study, and the requirement for written informed consent was waived due to its retrospective design. We searched the Electronic Medical Record system to include all the patients who received initial surgery and were diagnosed with OCCC at our institution from 2008 to 2018. The inclusion criteria were listed as follows: 1) A pathologically confirmed diagnosis of OCCC; 2) No preoperative treatment, including chemotherapy; 3) Without autoimmune diseases, systemic diseases, and serious diseases; 4) Without any sign of infection.

Early-stage patients received comprehensive staging surgery, while advanced patients underwent debulking surgery. All patients received paclitaxel and carboplatinbased chemotherapy. Platinum resistance was identified as progression within 6 months after the last platinum treatment, whereas platinum-refractory status was defined as progression during chemotherapy. Overall survival (OS) was calculated as the time interval from initial surgery to death or last contact. Progression-free survival (PFS) was defined as the time interval from initial surgery to the date of the first recurrence.

The time interval from blood collection to surgery is typically less than 7 days. Preoperative leukocyte differential counts (neutrophils, monocyte, and lymphocyte), platelet, serum albumin, plasma D-dimer and CA-125 were retrospectively abstracted from the medical records. NLR was defined as absolute neutrophil count divided by absolute lymphocyte count. MLR defined as was the ratio of absolute monocyte count and absolute lymphocyte count, and PLR was defined as absolute platelet count divided by absolute lymphocyte count.

\section{Statistical analysis}

Descriptive statistics were used to present clinicopathological variables. Medians and ranges are reported for continuous variables, while proportions are used for categorical data. Receiver operating characteristic (ROC) curves were used to obtain optimal albumin, D-dimer, CA125 and SIR marker cutoff values for predicting platinum response. Baseline characteristics were compared using Mann-Whitney U test for skewed data. Survival time was estimated using the Kaplan-Meier model, whereas Cox regression was conducted for multivariate analysis. Variables with statistical significance of univariate analysis were included in multivariate analyses. All $P$-values reported were two-tailed, and $P<0.05$ was considered statistically significant.

ROC curves and Kaplan-Meier curves were plotted using GraphPad Prism (Version 6.0, GraphPad Software, Inc., La Jolla, CA, USA). All other statistical analyses were performed with Statistical Package for Social Science (SPSS) (Version 20.0, SPSS, Inc., Chicago, IL, USA).

\section{Result}

Relations between preoperative hematological biomarkers and clinicopathological characteristics

A total of 91 OCCC participants who received initial surgery in our institution were identified for inclusion, 
and seven were excluded based on FIGO IA-IB stage. Eighty-four cases were enrolled in the analysis. The median age of the patients was 52 years (range, 26 to 83 years). In total, $44.0 \%(37 / 84)$ of the patients presented with late-stage tumors (FIGO III + IV). Optimal debulking was achieved in 91.7\% (77/84) patients. Eighty-two cases were available for platinum response assessment, and 2 patients were lost to follow-up during chemotherapy. In terms of chemotherapy response, 29.3\% (24/82) patients were classified as platinum resistant, and $70.7 \%$ (58/82) were classified as platinum sensitive. The median follow-up time was 28 months (range, 1 to 128 months).

Table 1 shows the median and range for leukocyte differential counts, CA125, albumin, D-dimer, and SIR markers based on tumor characteristics. Generally, preoperative CA125, albumin, D-dimer, and SIR markers were significantly associated with FIGO stage, residual tumor, and platinum response. Neutrophilia; monocytosis; lymphopenia; elevated NLR, MLR, PLR, and CA-125 levels; and decreased albumin levels were associated with advanced-stage disease and suboptimal debulking. Preoperative D-dimer levels were not directly linked to the availability of optimal debulking. Elevated CA125, Ddimer, NLR, and MLR levels and low albumin levels were associated with platinum resistance $(P<0.05)$. Interestingly, platelet count was independent of FIGO stage, residual tumor, and platinum resistance. Lymphocyte count was also independent of platinum resistance. Therefore, PLR exhibited no significant difference in platinumsensitive and platinum-resistance patients $(P=0.060)$.

ROC curves for platinum-based chemotherapy outcome prediction were generated to verify the optimal cut-off point for CA125, albumin, D-dimer, and NLR, MLR. The area under the curve (AUC) and the best cut-off values were established by plotting ROC curves (Table 2 and Fig. 1). The AUC of these curves ranged from the lowest value of 0.676 (albumin) to the highest value of 0.761 (Ddimer). The cut-off value, sensitivity, specificity of albumin to predict platinum resistance were $\leq 39.6 \mathrm{~g} / \mathrm{l}, 58.3$, and $74.1 \%$, respectively. The corresponding D-dimer and NLR values were $>3.27 \mathrm{mg} / \mathrm{l}, 58.3$, and $84.5 \%$ as well as $>2.28$, 87.5 , and $48.3 \%$, respectively.

\section{Prognostic factors influencing long-term survival with platinum-based chemotherapy}

We found that preoperative CA125, albumin, and Ddimer levels were significant prognostic indicators for OS and PFS. CA125 > 135.2 U/ml, albumin < $39.6 \mathrm{~g} / \mathrm{l}$, and D-dimer $>3.27 \mathrm{mg} / \mathrm{l}$ were associated with shorter PFS and $\mathrm{OS}(P<0.05)$. In the univariate analysis, only NLR among the SIR markers had prognostic significance for PFS $(P=0.007)$. Multivariate analysis was performed on all these factors to eliminate the confounding effect. On multivariate analysis, patients with D-dimer $>3.27 \mathrm{mg} / \mathrm{l}$
( $P=0.001$ for OS and $P=0.040$ for PFS) and albumin $<$ $39.6 \mathrm{~g} / \mathrm{l}(P=0.005$ for $\mathrm{OS}$ and $P=0.041$ for $\mathrm{PFS})$ retained significance, respectively (Table 3 and Fig. 2a, b). CA125 was not highly correlated with OS $(P=0.074)$ and PFS $(P=0.054)$, and NLR $(P=0.103)$ was not related to PFS after adjusting for confounding variables.

Then, we further stratified patients into three groups based on cut-off values of albumin (ALB) and D-dimer (D2). ALB lower than or D2 higher than the cut-off value was defined as abnormal. The grouping basis is as follows: group 1 = both normal (high ALB/low D2); group $2=$ one abnormal (high ALB/high D2 and low ALB/low D2); group 3 = both abnormal (low ALB/high D2). The survival curves for the three groups are shown in Fig. 2c. Cox regression analysis showed that the risk of disease progression was 2.766-fold (95\% CI, 1.362 5.615 ) and 4.395 -fold $\{95 \%$ confidence interval (CI), $1.906 \sim 10.132\}$ increased in groups 2 and 3 compared with group 1 . The risk of death was 4.264 -fold (95\% CI, $1.648 \sim 11.032$ ) and 12.029-fold (95\% CI, $4.158 \sim 34.796)$ increased, respectively (Fig. 3).

\section{Discussion}

Inflammation may play an important role in cancer progression. Increased neutrophils could promote tumor proliferation, angiogenesis, and invasion [14], whereas reduced lymphocyte levels indicate immune deficiency [15]. Therefore, the NLR reflects both inflammation and the immune system. A high pretreatment NLR is an adverse prognostic indicator for both the early and advanced stages of several malignancies $[10,16]$. Emerging evidence showed that SIR markers, such as NLR, PLR, and MLR, were associated with the prognosis of ovarian cancer patients $[17,18]$. To date, few reliable preoperative biomarkers that predict resistance or prognosis in OCCC have been identified. Four studies on the effectiveness of SIR markers in OCCC patients have been reported in the last 5 years, as shown in Table 4 . Concerning NLR, most of the previous reports suggested that NLR was a prognostic indicator for PFS and/or OS $[13,19,20]$. There are some conflicting results regarding PLR. One study suggested that high PLR was associated with unfavorable outcomes, advanced stage, resistance to primary treatment, and decreased survival [19], whereas other studies did not. One of the studies found that the lymphocyte-to-monocyte ratio was an independent predictor of OS, whereas NLR and PLR were not [21].

In the present study, in addition SIR markers, we conducted a comprehensive analysis of blood cells and biochemical indicators, which might be related to OCCC patient survival. The most interesting finding was that despite a significant increase in preoperative platelets in OCCC patients, it was not associated with staging, availability of optimal surgery, or platinum resistance. 
Table 1 Patient characteristics in relation to preoperative blood parameters and SIR marks

\begin{tabular}{|c|c|c|c|c|c|c|c|c|c|c|c|}
\hline \multirow[t]{2}{*}{ Characteristic } & \multirow[t]{2}{*}{$N^{a}(\%)$} & \multirow[t]{2}{*}{$\mathrm{CA} 125^{\mathrm{b}}(\mathrm{U} / \mathrm{ml})$} & \multirow{2}{*}{$\begin{array}{l}\text { Albumin }{ }^{\text {b }} \\
(\mathrm{g} / \mathrm{l})\end{array}$} & \multicolumn{3}{|c|}{ Leukocyte differential counts ${ }^{\mathrm{b}}(\mathrm{k} / \mu \mathrm{l})$} & \multirow{2}{*}{$\begin{array}{l}\text { Platelet }{ }^{\mathrm{b}} \\
(\mathrm{K} / \mu \mathrm{l})\end{array}$} & \multirow{2}{*}{$\begin{array}{l}\text { D-dimer }{ }^{b} \\
(\mathrm{mg} / \mathrm{l})\end{array}$} & \multicolumn{3}{|l|}{ Ratio $^{b}$} \\
\hline & & & & Lymphocyte & Monocyte & Neutrophil & & & NLR & MLR & PLR \\
\hline All cases & 84 & $\begin{array}{l}187.9(6.5- \\
\left.5000^{*}\right)\end{array}$ & $\begin{array}{l}40.7(25.9- \\
52.1)\end{array}$ & $1.5(0.4-2.9)$ & $\begin{array}{l}0.4(0.03- \\
1.6)\end{array}$ & $\begin{array}{l}4.1(1.9- \\
15.2)\end{array}$ & $\begin{array}{l}299(124- \\
608)\end{array}$ & $\begin{array}{l}1.66(0.19- \\
55.20)\end{array}$ & $\begin{array}{l}2.7(1.1- \\
20.3)\end{array}$ & $\begin{array}{l}0.28(0.03- \\
2.00)\end{array}$ & $\begin{array}{l}193.9(77.5- \\
955.0)\end{array}$ \\
\hline \multicolumn{12}{|l|}{ Age (years) } \\
\hline$\leq 52$ & $\begin{array}{l}42 \\
(50)\end{array}$ & $\begin{array}{l}188.0 \\
2854)\end{array}$ & $\begin{array}{l}40.7 \text { (33.1- } \\
49.4)\end{array}$ & $1.5(0.6-2.9)$ & $\begin{array}{l}0.4(0.2- \\
1.0)\end{array}$ & $\begin{array}{l}4.0(1.9- \\
12.2)\end{array}$ & $\begin{array}{l}301(124- \\
500)\end{array}$ & $\begin{array}{l}1.66(0.19- \\
55.20)\end{array}$ & $\begin{array}{l}2.6(1.1- \\
20.3)\end{array}$ & $\begin{array}{l}0.25(0.12- \\
0.83)\end{array}$ & $\begin{array}{l}201.7(77.5- \\
615.0)\end{array}$ \\
\hline$>52$ & $\begin{array}{l}42 \\
(50)\end{array}$ & $\begin{array}{l}165.0(11.1- \\
\left.5000^{*}\right)\end{array}$ & $\begin{array}{l}40.4(25.9- \\
52.1)\end{array}$ & $1.5(0.4-2.4)$ & $\begin{array}{l}0.4(0.03- \\
1.6)\end{array}$ & $\begin{array}{l}4.4(1.9- \\
15.2)\end{array}$ & $\begin{array}{l}296(147- \\
608)\end{array}$ & $\begin{array}{l}1.66(0.20- \\
20.00)\end{array}$ & $\begin{array}{l}2.8(1.1- \\
20.3)\end{array}$ & $\begin{array}{l}0.32(0.03- \\
2.00)\end{array}$ & $\begin{array}{l}191.0(92.1- \\
955.0)\end{array}$ \\
\hline$P$ value & & 0.589 & 0.056 & 0.874 & 0.039 & 0.826 & 0.871 & 0.756 & 0.826 & 0.053 & 0.940 \\
\hline \multicolumn{12}{|l|}{ FIGO stage } \\
\hline $\mid C-\|$ & $\begin{array}{l}47 \\
(56.0)\end{array}$ & $\begin{array}{l}70.5(6.5- \\
1930.0)\end{array}$ & $\begin{array}{l}43.6(29.6- \\
52.1)\end{array}$ & $1.5(0.9-2.9)$ & $\begin{array}{l}0.4(0.03- \\
1.0)\end{array}$ & $\begin{array}{l}3.6(1.9- \\
10.7)\end{array}$ & $\begin{array}{l}292(124- \\
500)\end{array}$ & $\begin{array}{l}1.49(0.19- \\
55.20)\end{array}$ & $\begin{array}{l}2.2(1.1- \\
7.1)\end{array}$ & $\begin{array}{l}0.21(0.03- \\
0.67)\end{array}$ & $\begin{array}{l}167.5(77.5- \\
500.0)\end{array}$ \\
\hline III-IV & $\begin{array}{l}37 \\
(44.0)\end{array}$ & $\begin{array}{l}276.9(45.6- \\
\left.5000^{*}\right)\end{array}$ & $\begin{array}{l}39.2(25.9- \\
49.2)\end{array}$ & $1.4(0.4-2.4)$ & $\begin{array}{l}0.4(0.3- \\
1.6)\end{array}$ & $\begin{array}{l}4.6(1.9- \\
15.2)\end{array}$ & $\begin{array}{l}311(147- \\
608)\end{array}$ & $\begin{array}{l}2.61(0.69- \\
11.03)\end{array}$ & $\begin{array}{l}3.2(1.1- \\
20.3)\end{array}$ & $\begin{array}{l}0.33(0.18- \\
2.00)\end{array}$ & $\begin{array}{l}230.0(101.7- \\
955.0)\end{array}$ \\
\hline$P$ value & & $<0.001$ & $<0.001$ & 0.031 & 0.002 & 0.009 & 0.320 & 0.001 & 0.001 & $<0.001$ & 0.006 \\
\hline \multicolumn{12}{|c|}{ Residual tumor $(\mathrm{cm})$} \\
\hline 0 & $\begin{array}{l}63 \\
(75.0)\end{array}$ & $\begin{array}{l}157.4(6.5- \\
\left.5000^{*}\right)\end{array}$ & $\begin{array}{l}41.7(28.3- \\
52.1)\end{array}$ & $1.5(0.6-2.9)$ & $\begin{array}{l}0.4(0.03- \\
1.6)\end{array}$ & $\begin{array}{l}3.8(1.9- \\
15.2)\end{array}$ & $\begin{array}{l}292(124- \\
608)\end{array}$ & $\begin{array}{l}1.66(0.19- \\
55.20)\end{array}$ & $\begin{array}{l}2.4(1.1- \\
7.1)\end{array}$ & $\begin{array}{l}0.25(0.03- \\
0.70)\end{array}$ & $\begin{array}{l}173.5(77.5- \\
500)\end{array}$ \\
\hline$\leq 1$ & $\begin{array}{l}14 \\
(16.7)\end{array}$ & $\begin{array}{l}371.4(45.6- \\
1845.3)\end{array}$ & $\begin{array}{l}38.4(29.0- \\
43.7)\end{array}$ & $1.4(0.9-2.4)$ & $\begin{array}{l}0.5(0.3- \\
0.9)\end{array}$ & $\begin{array}{l}4.7(2.7- \\
6.6)\end{array}$ & $\begin{array}{l}318(202- \\
593)\end{array}$ & $\begin{array}{l}2.53(0.69- \\
9.30)\end{array}$ & $\begin{array}{l}3.2(1.3- \\
5.7)\end{array}$ & $\begin{array}{l}0.35(0.19- \\
0.82)\end{array}$ & $\begin{array}{l}219.8(107.1- \\
539.1)\end{array}$ \\
\hline$>1$ & $7(8.3)$ & $\begin{array}{l}475.1(151.6- \\
1866.0)\end{array}$ & $\begin{array}{l}33.2(25.9- \\
49.2)\end{array}$ & $0.9(0.4-1.8)$ & $\begin{array}{l}0.6(0.3- \\
1.4)\end{array}$ & $\begin{array}{l}8.1(2.7- \\
12.2)\end{array}$ & $\begin{array}{l}342(253- \\
382)\end{array}$ & $\begin{array}{l}3.29(0.75- \\
6.06)\end{array}$ & $\begin{array}{l}8.2(2.8- \\
20.3)\end{array}$ & $\begin{array}{l}0.67(0.39- \\
2.00)\end{array}$ & $\begin{array}{l}383.3(190.0- \\
955.0)\end{array}$ \\
\hline$P$ value & & 0.007 & 0.006 & 0.008 & 0.002 & 0.005 & 0.314 & 0.064 & $<0.001$ & $<0.001$ & 0.004 \\
\hline \multicolumn{12}{|c|}{ Platinum response } \\
\hline Sensitive & $\begin{array}{l}58 \\
(69.0)\end{array}$ & $\begin{array}{l}124.6(6.47- \\
\left.5000^{*}\right)\end{array}$ & $\begin{array}{l}41.7(29.0- \\
52.1)\end{array}$ & $1.5(0.6-2.9)$ & $\begin{array}{l}0.4(0.03- \\
1.0)\end{array}$ & $\begin{array}{l}3.8(1.9- \\
10.7)\end{array}$ & $\begin{array}{l}279(124- \\
500)\end{array}$ & $\begin{array}{l}1.66(0.19- \\
20.00)\end{array}$ & $\begin{array}{l}2.4(1.1- \\
7.1)\end{array}$ & $\begin{array}{l}0.25(0.03- \\
0.70)\end{array}$ & $\begin{array}{l}176.7(77.5- \\
500.0)\end{array}$ \\
\hline resistant & $\begin{array}{l}24 \\
(28.6)\end{array}$ & $\begin{array}{l}294.3(38.21- \\
1866.0)\end{array}$ & $\begin{array}{l}39.2(25.9- \\
49.2)\end{array}$ & $1.5(0.4-2.4)$ & $\begin{array}{l}0.5(0.2- \\
1.6)\end{array}$ & $\begin{array}{l}4.9(2.1- \\
15.2)\end{array}$ & $\begin{array}{l}316(202- \\
608)\end{array}$ & $\begin{array}{l}3.82(0.44- \\
55.20)\end{array}$ & $\begin{array}{l}3.2(1.1- \\
20.3)\end{array}$ & $\begin{array}{l}0.35(0.15- \\
2.00)\end{array}$ & $\begin{array}{l}214.3(126.3- \\
955.0)\end{array}$ \\
\hline$P$ value & & 0.002 & 0.012 & 0.400 & 0.011 & 0.003 & 0.157 & $<0.001$ & 0.002 & 0.004 & 0.060 \\
\hline
\end{tabular}

Abbreviations: SIR systemic inflammatory response, NLR neutrophil to lymphocyte ratio, MLR monocyte to lymphocyte ratio, $P L R$ platelet to lymphocyte ratio

$P$ values with statistical significance were denoted

a Categorical data are shown in absolute value and proportion

${ }^{\mathrm{b}}$ Continuous variables are represented by median and range

* The upper limit of CA125 detection is 5000

Similarly, no correlation was noted between platinum resistance and preoperative lymphocyte count. Thus, PLR is not related to resistance or survival, which is consistent with most relevant studies [12, 13, 20]. Preoperative NLR level was associated with postoperative indicators, such as FIGO stage, residual tumor, and platinum resistance, which are known prognostic factors in OCCC [5]. The difference was that although univariate analysis showed NLR was significantly associated with PFS, the relation was not supported by multivariate analysis, indicating that NLR is not an independent predictor of survival. This discrepancy was potentially attributed to

Table 2 Predictive values of preoperative blood parameters and NLR, MLR for determination of platinum resistance

\begin{tabular}{lllllllll}
\hline Variables & AUC & $P$ & $95 \% \mathrm{Cl}$ & Cut-off value & Se\% & Sp\% & PPV\% & NPV\% \\
\hline MLR & 0.701 & $\mathbf{0 . 0 0 4}$ & $0.577-0.825$ & 0.3 & 62.5 & 70.7 & 46.9 & 82.0 \\
NLR & 0.710 & $\mathbf{0 . 0 0 3}$ & $0.589-0.832$ & 2.28 & 87.5 & 48.3 & 41.2 & 90.3 \\
ALB & 0.676 & $\mathbf{0 . 0 1 3}$ & $0.547-0.804$ & 39.6 & 58.3 & 74.1 & 81.1 & 48.3 \\
CA125 & 0.713 & $\mathbf{0 . 0 0 3}$ & $0.601-0.825$ & 135.15 & 91.7 & 51.7 & 44.0 & 93.8 \\
D2 & 0.761 & $<\mathbf{0 . 0 0 1}$ & $0.646-0.876$ & 3.27 & 58.3 & 84.5 & 60.9 & 83.1 \\
\hline
\end{tabular}

Abbreviations: MLR monocyte to lymphocyte ratio, NLR neutrophil to lymphocyte ratio, $A L B$ albumin, CA125 carbohydrate antigen $125, D 2$ D-dimer, $A U C$ area under the curve, $C l$ confidence interval, Se sensitivity, Sp specificity, $P P V$ positive predictive value, NPV negative predictive value

$P$ values with statistical significance were denoted 


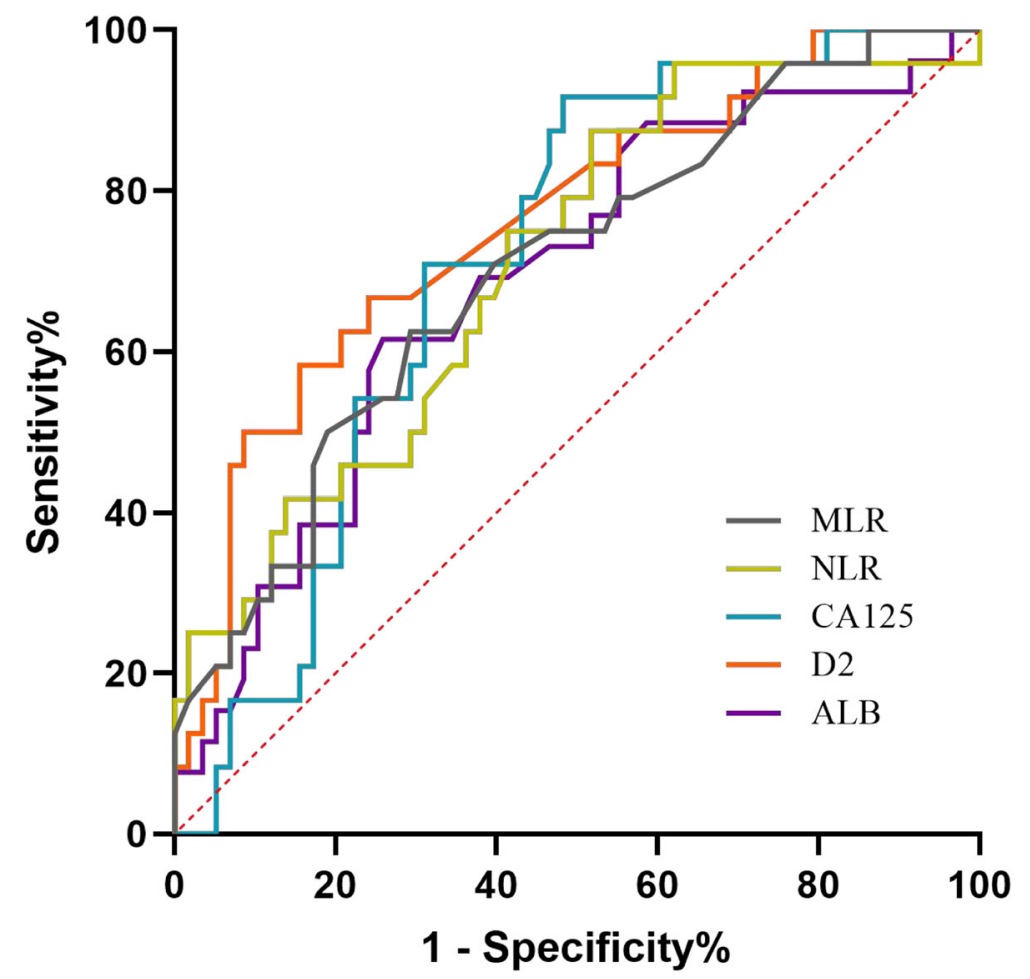

Fig. 1 Receiver operating characteristic curve demonstrating the AUC of preoperative MLR, NLR, CA125, D2, and ALB for platinum resistance. (Abbreviations: AUC, the area under the curve; MLR, monocyte-to-lymphocyte ratio; NLR, neutrophil to lymphocyte ratio; CA125, carbohydrate antigen 125; D2, D-dimer; ALB, albumin)

sample size differences and the different cut-off values used. In the present study, the proportion of patients with advanced-stage and platinum-resistant disease was the highest, and the NLR cut-off value was determined by whether patients were platinum sensitive or resistant. The original intention of the design is to address the major obstacle in the treatment of OCCC, which remains resistance to platinum-based chemotherapy. The finding suggests that a high NLR caused by an increased level of neutrophils reduce the response to adjuvant chemotherapy. However, its effect on PFS is influenced by additional factors.
Using stepwise comparison of prognostic values among the potential markers, we sought to identify the most dominant markers related to chemotherapy resistance and clinical outcomes in IC-IV OCCC. We found that preoperative D-dimer and albumin levels in OCCC patients were significantly correlated with platinum resistance and were independent predictors of PFS and OS. Patients with cancer often exhibit a state of hypercoagulation and exaggerated fibrinolysis [22]. D-dimer, as an end product of fibrinogen, is a signal of the activated coagulation system in numerous cancer types especially in the advanced stage $[23,24]$. Emerging studies

Table 3 Univariate and multivariate cox proportional analysis regarding overall survival and progression free survival

\begin{tabular}{|c|c|c|c|c|c|c|c|c|c|c|c|c|}
\hline \multirow[t]{3}{*}{ Variables } & \multicolumn{6}{|l|}{ OS } & \multicolumn{6}{|l|}{ PFS } \\
\hline & \multicolumn{3}{|c|}{ Univariate analysis } & \multicolumn{3}{|c|}{ Multivariate analysis } & \multicolumn{3}{|c|}{ Univariate analysis } & \multicolumn{3}{|c|}{ Multivariate analysis } \\
\hline & $\mathrm{HR}$ & $95 \% \mathrm{Cl}$ & $P$ & $\overline{\mathrm{HR}}$ & $95 \% \mathrm{Cl}$ & $P$ & $\mathrm{HR}$ & $95 \% \mathrm{Cl}$ & $P$ & $\mathrm{HR}$ & $95 \% \mathrm{Cl}$ & $P$ \\
\hline$\overline{M L R} \leq 0.30$ vs. $>0.30$ & / & / & 0.061 & / & / & 0.882 & / & I & 0.079 & / & / & 0.943 \\
\hline $\mathrm{NLR} \leq 2.28$ vs. $>2.28$ & / & / & 0.121 & / & / & 0.854 & 2.767 & $1.320-5.800$ & 0.007 & / & / & 0.103 \\
\hline CA125 $\leq 135.2$ vs. $>135.2$ & 3.828 & $1.468-9.983$ & 0.006 & / & / & 0.074 & 2.665 & $1.306-5.436$ & 0.007 & 2.057 & $0.989-4.282$ & 0.054 \\
\hline ALB $\leq 39.6$ vs. $>39.6$ & 0.279 & $0.134-0.584$ & 0.001 & 0.345 & $0.163-0.731$ & 0.005 & 0.404 & $0.220-0.743$ & 0.004 & 0.521 & $0.279-0.973$ & 0.041 \\
\hline $\mathrm{D} 2 \leq 3.27$ vs. $>3.27$ & 5.118 & $2.273-11.520$ & $<0.001$ & 4.092 & $1.809-9.254$ & 0.001 & 2.552 & $1.365-4.773$ & 0.003 & 1.959 & $1.032-3.717$ & 0.040 \\
\hline
\end{tabular}

Abbreviations: PFS progression-free survival, OS overall survival, MLR monocyte to lymphocyte ratio, NLR neutrophil to lymphocyte ratio, $A L B$ albumin, CA125 carbohydrate antigen 125, D2 D-dimer, $H R$ hazard ratio, $\mathrm{Cl}$ confidence interval

$P$ values with statistical significance were denoted 


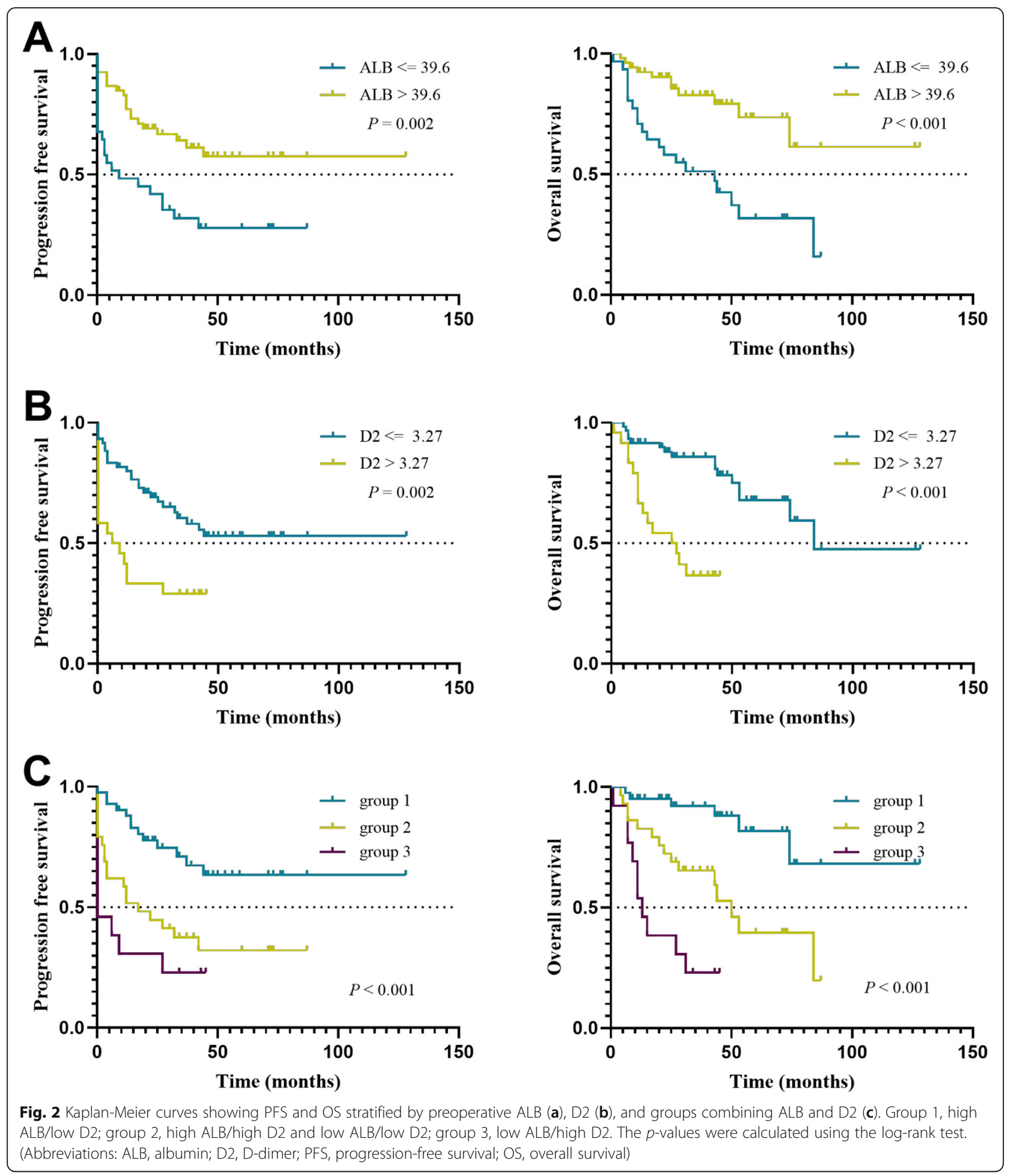

also suggest that a high pretreatment plasma D-dimer levels are a poor prognostic factor in EOC $[8,25]$. Regarding OCCC patients, in whom D-dimer levels are generally elevated and are more pronounced compared with other EOC patients, much attention has been paid to the relationship between D-dimer and venous thromboembolism $[7,26]$. The present study reported that a D-dimer cut-off value of 3.27 is a useful predictor of chemoresistance and can be used as an independent predictor of PFS and OS in clear cell ovarian cancer patients. On the other hand, pretreatment hypoalbuminemia, which is the outcome of 


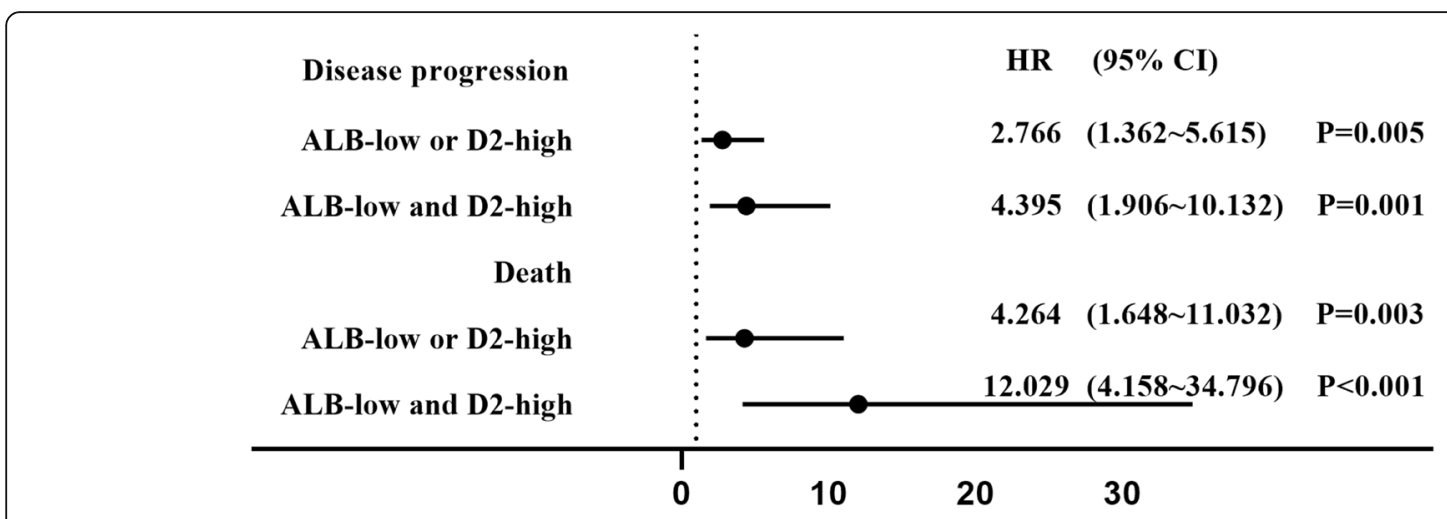

Fig. 3 The risk of disease progression and death compared to ALB-high and D2-low. (Abbreviations: ALB, albumin; D2, D-dimer)

malnutrition and cachexia in cancer patients due to the host responses to the tumor, also provides prognostic significance in OCCC [20]. Consistent with previous studies, we found out that hypoalbuminemia (albumin cut-off point of 39.6) and D-dimers acted as independent predictors of PFS and OS. Moreover, the risk of disease progression and death significantly increased if either the albumin or D-dimer cut-off value was surpassed. The corresponding risks of patients who reached albumin and D-dimer cut-off values were 4-fold and 12-fold increased, respectively, compared with those who did not. Thus, D-dimer and albumin may play an important role in selecting patients for adjuvant anti-cancer therapy. For OCCC patients with a high possibility of platinum resistance, high recurrence rate, and mortality, it is worth discussing whether early intervention using other antitumor therapies, such as targeted drugs, should be considered.

Pretreatment plasma D-dimer and albumin levels were each identified as prognostic factors for several malignancies [23, 24, 27], including ovarian cancer $[9,25]$; however, few studies have combined them to assess their role in chemoresistance. Given that OCCC exhibits increased D-dimer expression compared with other ovarian cancers, this combined evaluation seems to be more valuable in OCCC patients. Nevertheless, their AUCs were not greater than 0.8 , indicating that these findings could not be directly applied to clinical practice. Current studies that have reported that HE4 and mesothelin could be used as ovarian tumor markers [28-31]. Additionally, one study showed that HE4 protein promoted the proliferation of ovarian cancer cells and resistance to carboplatin in vitro, suggesting the value of HE4 in predicting the growth potential of epithelial ovarian cancer tumors and platinum resistance [32]. It is hoped that more potential biomarkers can be used and combined to improve the sensitivity and specificity of the evaluation. Further validation of these easily available parameters as promising prognostic biomarkers for patients with OCCC in prospective studies is encouraged.

The present study presents several limitations. First, selection and surveillance biases in our analysis could not be controlled due to the retrospective study design of only 84 samples from a single academic institution. Second, although we excluded patients with any inflammatory condition, some hematological biomarkers may have been affected by the presence of unrecognized systemic inflammatory diseases. Third, some possible confounders affecting SIR markers and coagulation function were not assessed.

Table 4 Summary of studies examining SIR as prognostic factors in OCCC patients

\begin{tabular}{llllll}
\hline & Kim 2016 [19] & Zhang 2017 [20] & Kwon 2018 [12] & Yoshida 2019 [13] & The present study \\
\hline Sample size & 109 & 155 & 109 & 83 & 84 \\
Advanced-stage \% & 37.5 & 29 & 41.3 & 0 & 44 \\
platinum resistance \% & 18.3 & 12.9 & 22 & NA & 28.6 \\
Prognostic factor for PFS & NLR, PLR & NLR & None & None & None \\
Prognostic factor for OS & None & NLR & LMR & NA & None \\
Cut-off value & 4.44 for resistance & NA & & & 2.28 for res OS \\
& 2.8 for survival & & &
\end{tabular}

Abbreviations: SIR Systemic inflammatory response, NLR neutrophil to lymphocyte ratio, PLR platelet to lymphocyte ratio, $L M R$ lymphocyte to monocyte ratio, PFS progression-free survival, OS overall survival, NA not available 


\section{Conclusion}

Elevated levels of preoperative D-dimer and low albumin levels may be the most useful biomarkers of worse response to first-line platinum-based chemotherapy and poor clinical outcomes. Elevated NLR has some predictive value for platinum resistance, but its predictive effect on prognosis requires further large-scale prospective investigation.

\section{Abbreviations}

EOC: epithelial ovarian cancer; OCCC: ovarian clear cell carcinoma; FIGO: the International Federation of Gynecology and Obstetrics; SIR: systemic inflammatory response; NLR: neutrophil-to-lymphocyte ratio; MLR: monocyteto-lymphocyte ratio; CA125: carbohydrate antigen 125; PLR: platelets to lymphocyte ratio; ROC: receiver operating characteristic; PFS: progression-free survival; OS: overall survival; AUC: area under the curve; Cl: confidence interval

\section{Acknowledgments}

Not applicable.

\section{Authors' contributions}

All the authors contributed to the contraception and design of the study. Data curation: Shuang Ye, Wei Chen. Formal analysis: Wei Chen, Siyuan Zhong, Boer Shan. Funding acquisition: Shuang Ye. Investigation: Shuang Ye, Wei Chen, Shuling Zhou, Boer Shan, Xiaohua Wu, Huijuan Yang. Methodology: Boer Shan, Xiaohua Wu, Huijuan Yang. Project administration: Shuang Ye, Wei Chen, Siyuan Zhong, Boer Shan. Resources: Shuang Ye, Shuling Zhou, Siyuan Zhong, Boer Shan, Xiaohua Wu, Huijuan Yang. Software: Shuang Ye, Wei Chen. Supervision: Shuang Ye, Xiaohua Wu, Huijuan Yang. Validation: Shuang Ye, Wei Chen, Siyuan Zhong, Boer Shan Shuling Zhou. Visualization: Xiaohua Wu, Huijuan Yang. Roles/Writing original draft: Wei Chen. Writing - review \& editing: Shuang Ye, Xiaohua Wu, Huijuan Yang. All authors read and approved the final manuscript.

\section{Funding}

The study was supported by grants from National Natural Science Foundation of China (81702558) and Fudan University Shanghai Cancer Center (YJ201603). The funding bodies didn't participate in the design of the study and collection, analysis, and interpretation of data and in writing the manuscript.

\section{Availability of data and materials}

The dataset supporting the conclusions of this article is available upon request. Please contact Dr. Shuang Ye (mendy_ye@126.com).

\section{Ethics approval and consent to participate}

The study was approved by the Fudan University Shanghai Cancer Center review board and the requirement for written informed consent was waived due to its retrospective design.

\section{Consent for publication}

Not applicable.

\section{Competing interests}

The authors declare that they have no competing interests.

\section{Author details}

'Department of Gynecologic Oncology, Fudan University Shanghai Cancer Center, Shanghai, China. 'Department of Obstetrics and Gynecology, Minhang Hospital, Fudan University, the Central Hospital of Minhang District, Shanghai, China. ${ }^{3}$ Department of Pathology, Fudan University Shanghai Cancer Center, Shanghai, China. ${ }^{4}$ Department of Oncology, Shanghai Medical College, Fudan University, Shanghai 200032, China.
Received: 1 March 2020 Accepted: 28 July 2020

Published online: 08 August 2020

\section{References}

1. Siegel RL, Miller KD, Jemal A. Cancer statistics, 2018. CA Cancer J Clin. 2018; 68(1):7-30. https://doi.org/10.3322/caac.21442.

2. Anglesio MS, Carey MS, Köbel M, Mackay H, Huntsman DG. Clear cell carcinoma of the ovary: a report from the first ovarian clear cell symposium, June 24th, 2010. Gynecol Oncol. 2011;121(2):407-15. https://doi.org/10.1016/ j.ygyno.2011.01.005.

3. Glasspool RM, McNeish IA. Clear cell carcinoma of ovary and uterus. Curr Oncol Rep. 2013;15(6):566-72. https://doi.org/10.1007/s11912-013-0346-0.

4. del Carmen MG, Birrer M, Schorge JO. Clear cell carcinoma of the ovary: a review of the literature. Gynecol Oncol. 2012;126(3):481-90. https://doi.org/ 10.1016/j.ygyno.2012.04.021.

5. Bennett JA, Dong F, Young RH, Oliva E. Clear cell carcinoma of the ovary: evaluation of prognostic parameters based on a clinicopathological analysis of 100 cases. Histopathology. 2015;66(6):808-15. https://doi.org/10.1111/his. 12514.

6. Clark TG, Stewart ME, Altman DG, Gabra H, Smyth JF. A prognostic model for ovarian cancer. Br J Cancer. 2001;85(7):944-52.

7. Ebina Y, Uchiyama M, Imafuku H, Suzuki K, Miyahara Y, Yamada H. Risk factors for deep venous thrombosis in women with ovarian cancer. Medicine. 2018;97(23):e11009. https://doi.org/10.1097/MD. 0000000000011009

8. Liu P, Wang Y, Tong L, Xu Y, Zhang W, Guo Z, et al. Elevated preoperative plasma D-dimer level is a useful predictor of chemoresistance and poor disease outcome for serous ovarian cancer patients. Cancer Chemother Pharmacol. 2015;76(6):1163-71. https://doi.org/10.1007/s00280-015-2900-y.

9. Wu J, Fu Z, Liu G, Xu P, Xu J, Jia X. Clinical significance of plasma D-dimer in ovarian cancer: a meta-analysis. Medicine. 2017;96(25):e7062. https://doi.org/ 10.1097/MD.0000000000007062.

10. Templeton AJ, McNamara MG, Seruga B, Vera-Badillo FE, Aneja P, Ocana A, et al. Prognostic role of neutrophil-to-lymphocyte ratio in solid tumors: a systematic review and meta-analysis. J National Cancer Institute. 2014;106(6): dju124. doi:https://doi.org/10.1093/jnci/dju124.

11. Ethier JL, Desautels DN, Templeton AJ, Oza A, Amir E, Lheureux S. Is the neutrophil-to-lymphocyte ratio prognostic of survival outcomes in gynecologic cancers? A systematic review and meta-analysis. Gynecol Oncol. 2017;145(3):584-94. https://doi.org/10.1016/j.ygyno.2017.02.026.

12. Kwon BS, Jeong DH, Byun JM, Lee TH, Choi KU, Song YJ, et al. Prognostic value of preoperative lymphocyte-monocyte ratio in patients with ovarian clear cell carcinoma. J Cancer. 2018;9(7):1127-34. https://doi.org/10.7150/jca. 24057.

13. Yoshida K, Yoshikawa N, Shirakawa A, Niimi K, Suzuki S, Kajiyama H, et al. Prognostic value of neutrophil-to-lymphocyte ratio in early-stage ovarian clear-cell carcinoma. J Gynecol Oncol. 2019;30(6):e85. https://doi.org/10. 3802/jgo.2019.30.e85.

14. Ocana A, Nieto-Jiménez C, Pandiella A, Templeton AJ. Neutrophils in cancer: prognostic role and therapeutic strategies. Mol Cancer. 2017;16(1):137. https://doi.org/10.1186/s12943-017-0707-7.

15. Dunn GP, Old LJ, Schreiber RD. The immunobiology of cancer immunosurveillance and immunoediting. Immunity. 2004;21(2):137-48.

16. Mei Z, Shi L, Wang B, Yang J, Xiao Z, Du P, et al. Prognostic role of pretreatment blood neutrophil-to-lymphocyte ratio in advanced cancer survivors: a systematic review and meta-analysis of 66 cohort studies. Cancer Treat Rev. 2017;58:1-13. https://doi.org/10.1016/j.ctrv.2017.05.005.

17. Zhao Z, Zhao X, Lu J, Xue J, Liu P, Mao H. Prognostic roles of neutrophil to lymphocyte ratio and platelet to lymphocyte ratio in ovarian cancer: a meta-analysis of retrospective studies. Arch Gynecol Obstet. 2018;297(4): 849-57. https://doi.org/10.1007/s00404-018-4678-8.

18. Yang Z, Gu JH, Guo CS, Li XH, Yang WC. Preoperative neutrophil-tolymphocyte ratio is a predictor of survival of epithelial ovarian cancer: a systematic review and meta-analysis of observational studies. Oncotarget. 2017;8(28):46414-24. doi:https://doi.org/10.18632/oncotarget.16793.

19. Kim HS, Choi H-Y, Lee M, Suh DH, Kim K, No JH, et al. Systemic inflammatory response markers and CA-125 levels in ovarian clear cell carcinoma: a two center cohort study. Cancer Res Treatment. 2016;48(1): 250-8. https://doi.org/10.4143/crt.2014.324.

20. Zhang H, Lu J, Lu Y, Zhou J, Wang Z, Liu H, et al. Prognostic significance and predictors of the system inflammation score in ovarian clear cell 
carcinoma. PLoS One. 2017;12(5):e0177520. https://doi.org/10.1371/journal. pone.0177520.

21. Sierzega M, Lenart M, Rutkowska M, Surman M, Mytar B, Matyja A, et al. Preoperative neutrophil-lymphocyte and lymphocyte-monocyte ratios reflect immune cell population rearrangement in Resectable pancreatic Cancer. Ann Surg Oncol. 2017;24(3):808-15. https://doi.org/10.1245/s10434016-5634-0.

22. Lin Y, Liu Z, Qiu Y, Zhang J, Wu H, Liang R, et al. Clinical significance of plasma D-dimer and fibrinogen in digestive cancer: a systematic review and meta-analysis. Eur J Surg Oncol. 2018;44(10):1494-503. https://doi.org/10. 1016/j.ejso.2018.07.052.

23. Zhu LR, Li J, Chen P, Jiang Q, Tang XP. Clinical significance of plasma fibrinogen and D-dimer in predicting the chemotherapy efficacy and prognosis for small cell lung cancer patients. Clin Transl Oncol. 2016;18(2): 178-88. https://doi.org/10.1007/s12094-015-1350-7.

24. Li H, Zhao S, Jing Z, Li J, Shuanying Y, Zhang N. Combination of D-dimer and carcinoembryonic antigen levels as a predictive and prognostic biomarker in advanced colorectal cancer patients. J Cell Biochem. 2018. https://doi.org/10.1002/jcb.28087.

25. Yamada Y, Kawaguchi R, Iwai K, Niiro E, Morioka S, Tanase Y, et al. Preoperative plasma D-dimer level is a useful prognostic marker in ovarian cancer. J Obstetrics Gynaecol. 2020;40(1):102-6. https://doi.org/10.1080/ 01443615.2019 .1606176$.

26. Uno K, Homma S, Satoh T, Nakanishi K, Abe D, Matsumoto K, et al. Tissue factor expression as a possible determinant of thromboembolism in ovarian cancer. Br J Cancer. 2007;96(2):290-5.

27. Miura K, Hamanaka K, Koizumi T, Kitaguchi Y, Terada Y, Nakamura D, et al. Clinical significance of preoperative serum albumin level for prognosis in surgically resected patients with non-small cell lung cancer: comparative study of normal lung, emphysema, and pulmonary fibrosis. Lung Cancer. 2017;111:88-95. https://doi.org/10.1016/j.lungcan.2017.07.003.

28. Chudecka-Głaz AM, Cymbaluk-Płoska AA, Menkiszak JL, Sompolska-Rzechuła AM, Tołoczko-Grabarek Al, Rzepka-Górska IA. Serum HE4, CA125, YKL-40, bcl2, cathepsin-L and prediction optimal debulking surgery, response to chemotherapy in ovarian cancer. J Ovarian Res. 2014;7:62. https://doi.org/10. 1186/1757-2215-7-62.

29. Aarenstrup Karlsen M, Høgdall C, Nedergaard L, Philipsen Prahm K, Schou Karlsen NM, Weng Ekmann-Gade A, et al. HE4 as a predictor of adjuvant chemotherapy resistance and survival in patients with epithelial ovarian cancer. APMIS. 2016;124(12):1038-45. https://doi.org/10.1111/apm.12625.

30. Madeira K, Dondossola ER, Farias BFDE, Simon CS, Alexandre MCM, Silva BR, et al. Mesothelin as a biomarker for ovarian carcinoma: a meta-analysis. An Acad Bras Cienc. 2016;88(2):923-32. https://doi.org/10.1590/00013765201620150107.

31. Hanaoka T, Hasegawa K, Kato T, Sato S, Kurosaki A, Miyara A, et al. Correlation between tumor Mesothelin expression and serum Mesothelin in patients with epithelial ovarian carcinoma: a potential noninvasive biomarker for Mesothelin-targeted therapy. Mol Diagn Ther. 2017;21 (2):18798. https://doi.org/10.1007/s40291-017-0255-2.

32. Wang H, Zhu L, Gao J, Hu Z, Lin B. Promotive role of recombinant HE4 protein in proliferation and carboplatin resistance in ovarian cancer cells. Oncol Rep. 2015;33(1):403-12. https://doi.org/10.3892/or.2014.3549.

\section{Publisher's Note}

Springer Nature remains neutral with regard to jurisdictional claims in published maps and institutional affiliations.

Ready to submit your research? Choose BMC and benefit from:
- fast, convenient online submission
- thorough peer review by experienced researchers in your field
- rapid publication on acceptance
- support for research data, including large and complex data types
- gold Open Access which fosters wider collaboration and increased citations
- maximum visibility for your research: over 100M website views per year
At BMC, research is always in progress.
Learn more biomedcentral.com/submissions

